\title{
PENGARUH PENERAPAN PEMBELAJARAN INQUIRI DAN METODE DEIMONSTRASI TERHADAP HASIL BELAJAR PADA MATA PELAJARAN FIQHI PESERTA DIDIK KELAS XI DI MADRASAH ALIYAH GUPPI SAMATA KABUPATEN GOWA
}

\author{
Nurdalia, Susdiyanto, Sulaiman Saat \\ Pascasarjana UIN Alauddin Makassar, \\ Fakultas Tarbiyah dan Keguruan UIN Alauddin Makassar \\ Email: Nurdaliahabtang@gmail.com
}

\begin{abstract}
This problem aims to find out the application of inquiry learning on fiqhi subjects, find out the application of demonstration methods on fiqhi subjects, find out the learning outcomes on fiqhi subjects of class XI students after pre-test and post-test at Aliyah Guppi Samata Gowa District, to know the influence the application of inquiry learning on subjects, knowing the effect of applying the demonstration method on fiqhi subjects, knowing the effect of the application of inquiry learning and demonstration methods on fiqhi subjects of class XI students at the Aliyah Guppi Samata Madrasah in Gowa Regency simultaneously. This research is a quasi-experimental design by dividing the two groups, namely the experimental class and the control class which are chosen non-equivalently without randomization, then given a pre-test to find out what is the initial difference between the control class and the experimental class, after which through post-test on the control class and experiment. This study uses quantitative analysis, in Aliyah Guppi Samata Madrasah Gowa Regency, amounting to 40 students, the method of data collection is taken in three ways, namely observation, tests and documentation. Data processing techniques were first tested for validity, reliability of the test items collected in the field, then analyzed descriptively statistically, inferential tests (consisting of normality test, linearity test), hypothesis testing (including simple regression analysis and multiple regression analysis. First, the results of the study state that the application of inquiry learning can improve the learning outcomes of fiqhi subjects, the second application of demonstration methods can improve learning outcomes in fiqhi subjects, thirdly obtain inquiry learning learning outcomes more significantly than the control class on variable $X$. Pretest IV in the value control class the average is 54.95, the application of inquiry learning has an average score of 60.35, post-test IV in the control class has an average score of 62.7, the application of inquiry learning has an average value of 79.00, then the application of the demonstration method is more significant compared to the control class in Variable X 2. Pretest IV in the control class the average value was 52.55, the demonstration method averaged 65.30. Post-test IV test in the control class averaged 51.65, and the demonstration method averaged 74.30, fourth obtained the influence of the determination coefficient of $71.8 \%$, fifth, there was an influence between the application of demonstration methods to learning outcomes fiqhi subjects in Aliyah Madrasah Guppi Samata Gowa Regency, the magnitude of the influence of the determination coefficient of $78.1 \%$ and sixth there is a joint effect between the application of inquiry learning
\end{abstract}


and demonstration methods on learning outcomes fiqhi subjects in Madrasah Aliyah Guppi Samata Gowa Regency determination coefficient of 78.8\%.

Keywords: Inquiry Learning, Demonstration Method, Learning Outcomes of Fiqhi Subjects

\section{PENDAHULUAN}

\section{A. Latar Belakang}

$\mathrm{P}$ embelajaran adalah suatu proses dalam lingkungan yang secara sengaja dikelola untuk memungkinkan turut serta dalam tingkah laku tertentu dalam kondisi khusus atau menghasilkan respon terhadap situasi tertentu. ${ }^{1}$ Metode merupakan upaya mengimplementasikan rencana yang sudah disusun dalam kegiatan nyata agar tujuan yang telah disusun tercapai secara optimal. Metode digunakan untuk merealisasikan strategi yang telah ditetapkan. Metode adalah suatu tekhnik atau cara yang ditempuh untuk melakukan sesuatu agar lebih mudah dan memudahkan terhadap orang lain. ${ }^{2}$ Metode mempunyai kedudukan yang sangat penting dalam upaya mencapai tujuan dalam proses pembelajaran karena metode menjadi sarana dalam menyampaikan materi pelajaran yang tersusun dalam kurikulum, tanpa metode suatu materi pelajaran tidak akan dapat berproses secara efisien dan efektif dalam kegiatan pembelajaran menuju tujuan pendidikan. ${ }^{3}$ Seorang guru dituntut memiliki kemampuan dalam mengembangkan pendekatan, dan memilih metode pembelajaran yang efektif.

Metode pembelajaran yang di pakai di Madrasah Aliyah Guppi Samata adalah tanya jawab, resitasi, ceramah dan diskusi. Adapun permasalahan yang diperoleh berdasarkan observasi awal dari penerapan metode diskusi, tanya jawab, dan resitasi yaitu sebagian dari peserta didik yang mendominasi adalah peserta didik yang memiliki IQ yang tinggi atau cerdas, sebagian Peserta didik kurang memahami, pasif pada saat pemaparan materi sehingga mengganggu temannya yang sedang belajar dan di dukung sarana pembelajaran seperti buku yang tidak tersedia. Peneliti meneliti pembelajaran inquiri karena beberapa alasan yaitu pertama pembelajaran ini tidak pernah diterapkan, kedua memberikan keluwesan kepada peserta didik, ketiga menunjang perkembangan dan menambah wawasan atau mandiri menemukan sendiri jawabannya dan mengembankan Potensi peserta didik untuk menanamkan nilai-nilai keagamaan. Pembelajaran inquiri adalah pembelajaran yang menyajikan bahan tidak dalam bentuk final, tetapi peserta didik diberi peluang dan kesempatan untuk mencari dan menemukan sendiri jawabannya. ${ }^{4}$ Artinya dalam pembelajaran inquiri peserta didik diberi peluang untuk memecahkan sendiri pertanyaan sebagai bahan dalam pembelajaran dengan cara menemukan.

\footnotetext{
${ }^{1}$ Syaiful Sagala, Konsep dan Makna Pembelajaran untuk Membantu Memecahkan Problematika Belajar dan Mengajar (Cet. VIII; Bandung: Alfabeta, 2010), h. 61.

${ }^{2}$ Muhammad Yaumi, Prinsip-Prinsip Desain Pembelajaran (Cet. IV; Jakarta: Kencana Prenada Media Group, 2016), h. 231.

${ }^{3}$ M. Arifin, Ilmu Pendidikan Islam (Cet. II; Jakarta: PT. Bumi Aksara, 2006), h. 144.

${ }^{4}$ Ramyulis, Metodologi Pendidikan Islam (Cet. VII; Jakarta: Radar Jaya Ofset, 2012), h. 24.
} 
Pembelajaran inquiri menekankan pendidik sebagai pembimbing fasilitator dan peserta didik dituntut lebih aktif berperan dalam proses pembelajaran artinya transformasi ilmu dari materi pelajaran akan ditemukan sendiri oleh peserta didik kepeserta didik yang lain sehingga dampak positifnya dapat menciptakan suasana kelas yang lebih efektif. Observasi awal di Madrasah Aliyah Guppi Samata Kabupaten Gowa metode demonstrasi tidak pernah diterapkan khusus untuk kelas XI, akan tetapi kelas X dan XII sudah pernah diterapkan. Kesenjangan pada saat penerapan metode demonstrasi pada kelas X dan XII yaitu peserta didik sebagian kecil keluar masuk dalam kelas, hal ini karena peserta minoritas peserta didik kurang menyenangi dengan diterapnya metode demonstrasi. Beberapa pertimbangan peneliti menggunakan metode demonstrasi yaitu metode demonstrasi berpeluang untuk memfokuskan peserta didik dalam meningkatkan motivasi peserta didik, perhatian peserta didik lebih terpusat, melatih untuk mempraktekkan langsung apa yang diamati serta dalam pembelajaran peserta didik tidak hanya membutuhkan teori akan tetapi membutuhkan praktek agar peserta didik lebih cepat memahami isi dari materi pembelajaran. Perpaduan antara metode inquiri dan metode demonstrasi dapat menunjang keberhasilan dalam proses pembelajaran. Alat ukur penerapan metode demonstrasi dapat diketahui melalui baik atau buruknya pengimplementasian melalui praktek langsung terhadap Implikasi pemahaman, penguasaan, keterampilan dan sikap dapat diperoleh melalui praktek atau demonstrasi.

\section{B. Tujuan}

a. Untuk mendeskripsikan hasil belajar peserta didik kelas XI pada mata pelajaran fiqhi sebelum penerapan pembelajaran inquiri dan metode demonstrasi di Madrasah Aliyah Guppi Samata Kabupaten Gowa.

b. Untuk mendeskripsikan peningkatan hasil belajar peserta didik kelas XI pada mata pelajaran fiqhi setelah penerapan pembelajaran inquiri dan metode demonstrasi di Madrasah Aliyah Guppi Samata Kabupaten Gowa.

c. Untuk menganalisis dampak penerapan pembelajaran inkuiri dan metode demonstrasi terhadap hasil belajar pada mata pelajaran fiqhi peserta didik kelas XI di Madrasah Aliyah Guppi Samata Kabupaten Gowa.

\section{METODE PENELITIAN}

\section{A. Jenis Penelitian}

Jenis Penelitian ini merupakan penelitian eksperimen dengan jenis penelitian atau quasi-eksperimental design. Bentuk desain eksperimen yang digunakan dalam penelitian ini adalah desain kelompok kontrol non-ekuvalen atau the nonequivalent control group design.

\section{B. Desain Penelitian}

Desain kelompok kontrol non-ekuvalen atau the nonequivalent control group design dengan desain ini, baik kelompok esperimen maupun kelompok kontrol dibandingkan, kelompok tersebut dipilih dan ditempatkan tampa melalui randomisasi. 
Subjek penelitian terdiri dari 40 siswa peserta didik. 20 peserta didik dari siswa kelas $\mathrm{XI}_{\mathrm{A}}$ sebagai kelompok eksperimen dengan penerapan pembelajaran inquiri dan metode demonstrasi. 20 peserta didik dari siswa kelas $\mathrm{XI}_{\mathrm{B}}$ dengan penerapan metode ceramah (uji pretest), metode diskusi (uji post-test) di Madrasah Aliyah Guppi Samata Kabupaten Gowa.

\section{Lokasi Penelitian}

Lokasi penelitian ini dilaksanakan pada Madrasah Aliyah Guppi Samata Kabupaten Gowa.

\section{HASIL PENELITIAN}

\section{A. Pengertian Pembelajaran Inquiri}

Pembelajaran inquiri adalah rangkaian kegiatan pembelajaran yang menekankan pada proses berpikir secara kritis dan analitis untuk mencari, menemukan sendiri jawaban dari suatu masalah yang dipertanyakan. ${ }^{5}$ Pembelarajaran inquiri adalah pembelajaran untuk membimbing peserta didik menemukan jawaban dari materi pembelajaran. Membimbing merupakan memberikan pertolongan yang diberikan kepada peserta didik atau peserta didik yang telah dipersiapkan dengan pengetahuan, pemahaman, keterampilan terhadap materi yang kurang dipahami. ${ }^{6}$ Berdasarkan definisi Pembelajaran inquiri di atas dapat disimpulkan bahwa Pembelajaran inquiri adalah kegiatan pembelajaran dengan mengajukan pertanyaan-pertanyaan dan jawaban ditemukan melalui proses penemuan sendiri dari peserta didik. Penemuan sendiri yang bermakna tidak memberikan batasan kepada peserta didik untuk memperoleh informasi yang berkaitan dengan pertanyaan-pertanyaan yang terhadap judul tertentu. Menurut Wina Sanjaya langkah-langkah pembelajaran inquiri yaitu fase orientasi, merumuskan masalah, merumuskan hipotesis, mengumpulkan data, analisis data dan merumuskan kesimpulan.

\section{B. Kelebihan, Kelemahan dan Prinsip Pembelajaran Inquiri}

Kelebihan pembelajaran inquiri pertama mengembangkan potensi intelektual. Menurut Brunner, through the method inquiry, a student slowly learner how to organize and carry out the investigations. Melalui pembelajaran inquiri, peserta didik yang lambat belajar akan mengetahui bagaimana menyusun dan melakukan penyelidikan, kedua Mengubah peserta didik dari memiliki motivasi dari luar (extrinsic motivation) menjadi motivasi dalam diri sendiri, ketiga mempertahankan memori peserta didik artinya terjadinya peningkatan kemampuan mengingat ingatan pemahaman terhadap materi yang dipelajari oleh peserta didik. Langkah-langkahnya yaitu memberikan kebebasan dan peluang besar kepada peserta didik untuk menemukan sesuatu melalui proses asimilasi, akomodasi, kemempat Mengembangkan keterampilan proses peserta didik. Keterampilan

\footnotetext{
${ }^{5}$ Wina Sanjaya, Strategi Pembelajaran Beriorentasi Standar Proses Pendidikan (Jakarta: kencana Prenada Media Group, 2008), h. 196.

${ }^{6}$ Kartini Kartono, Bimbingan dan Dasar-Dasar Pelaksanaan; Tekhnik Bimbingan Praktis (Cet. I; Jakarta: CV. Rajawali, 1985), h. 9.
} 
proses adalah keterampilan yang diperoleh dari latihan-latihan kemampuan mental, fisik, sosial yang mendasar sebagai penggerak kemampuan yang lebih tinggi. ${ }^{7}$ Artinya pembelajaran inquiri mampu meningkatakan Kemampuan dasar yang telah dikembangkan dan telah terlatih lama-kelamaan dari proses penemuan akan menjadi satu keterampilan, kelima Memberikan waktu kepada peserta didik secukupnya sehingga mereka dapat mengasimilasikan dan mengakomodasi informasi. ${ }^{8}$ Keenam Mengembangkan sikap percaya diri, bertanggung jawab, dan rasa kesetiakawanan sosial dalam memecahkan masalah, dan ketujuh anak belajar berpikir analisis dan mencoba memecahkan problema yang dihadapi sendiri, kebiasaan ini akan ditransfer dalam kehidupan masyarakat. kelemahan pembelajaran inquiri pertama memerlukan waktu yang panjang, kedua Membutuhkan perencanaan yang teratur dan matang. ${ }^{9}$ Ketiga tidak efektif jika terdapat peserta didik yang pasif. Keempat Tidak mudah mendesainnya, karena terbentur pada kebiasaan belajar peserta didik Sulit mengontrol kegiatan dan keberhasilan peserta didik. ${ }^{10}$

prinsip penggunaan pembelajaran inquiri ada lima yaitu beriorentasi pada pengembagan intelektual, prinsip berinteraksi antara guru dan peserta didik, prinsip bertanya, prinsip belajar untuk berpikir. Adapun macam-macam atau jenis-jenis pelaksanaan inquiri terdiri dari inquiri terpimpin ((Guided Inquiry), inquiri bebas (Free Inquiry), inquiri bebas yang dimodifikasi (Modified Free Inquiry). Inquiry terpimpin atau Inquiry tingkat pertama merupakan kegiatan inquiri dimana masalah dikemukakan oleh guru atau bersumber dari buku teks kemudian peserta didik bekerja untuk menemukan jawaban terhadap masalah tersebut dibawah bimbingan yang intensif dari guru. Inquiri bebas peserta didik melakukan penelitian sendiri tugas guru adalah memotivasi peserta didik untuk mengemukakan gagasannya dan merancang. Inquiry bebas yang dimodifikasi dilakukan dengan cara pendidik memberikan masalah-masalah kemudian ditugaskan untuk memecahkan masalahnya.

\section{Pengertian Metode Demonstrasi}

Metode demonstrasi adalah metode yang ditempuh pendidik dengan cara mengatur, menyusun, cara pembuatan, proses mengamati alat-alat peraga, proses menyaksikan prosedur-prosedur suatu alat atau perkakas, mesin, sehingga dapat memilih dan meperbandingkan cara yang terbaik juga mengetahui kebenaran suatu teori di dalam praktek. ${ }^{11}$ Kesimpulannya metode demonstrasi adalah metode mengajar yang secara langsung pendidik memperagakan latihan praktik pembelajaran, peserta didik mengamati

${ }^{7}$ Jamil Suprihatiningrum, Strategi Pembelajaran; Teori dan Aplikasi (Jogjakarta: Ar-Ruzz Media, 2013), h. 170.

${ }^{8}$ Krismanto, Beberapa Tekhnik, Model Dan Strategi dalam Pembelajaran Matematika (Yogyakarta: PPPG Matematika, 2003), h. 45.

${ }^{9}$ H. Nasir A. Baki, Metode pembelajaran Agama Islam (Cet. I; Yogyakarta: Eja Publisher, 2014), h. 109.

${ }^{10}$ H. Nasir A. Baki, Metode pembelajaran Agama Islam, h.111.

${ }^{11}$ Roestiyah N.K, Strategi Belajar mengajar (Cet. V; Jakarta: Rineka Cipta, 1998), h. 83. 
langsung tata cara pelaksanaan pembelajaran melalui praktik dan sesudahnya peserta didik mempraktekkan sendiri pelajaran yang telah diamati sebelumnya. Untuk melaksanakan metode demonstrasi secara efektif dan efisien beberapa langkah yang harus dipahami dan digunakan oleh guru terdiri dari tahapan persiapan atau perencanaan, uji coba dan pelaksanaan oleh guru kemudian diikuti oleh peserta didik dan diakhiri dengan adanya evaluasi. $^{12}$

\section{Kelebihan dan Kelemahan Metode Demonstrasi}

Kelebihan metode demonstrasi pertama Perhatian peserta didik dapat dipusatkan kepada hal-hal yang dianggap penting oleh guru sehingga hal yang penting itu dapat diamati secara teliti, kedua dapat membimbing peserta didik kearah berpikir yang sama dalam satu saluran pikiran yang sama, ketiga mengurangi kesalahan-kesalahan bila dibandingkan dengan hanya membaca atau mendengarkan, keempat Persoalan yang menimbulkan pertanyaan atau keraguan dapat diperjelas waktu proses demonstrasi. Kelemahan metode demonstrasi Metode demonstrasi memerlukan persiapan yang lebih matang, memerlukan peralatan, bahan-bahan dan tempat yang memadai yang berarti penggunaan metode ini memerlukan pembiayaan yanng lebih mahal dibandingkan dengan metode konvensional, memerlukan kemampuan dan keterampilan pendidik yang khusus, sehingga pendidik dituntut untuk bekerja lebih profesional. ${ }^{13}$ Disamping itu demonstrasi juga memerlukan kemauan dan motivasi pendidik yang energik untuk keberhasilan proses pembelajaran, Penggunaan waktu yang lama akan menyita waktu jam pelajaran lain. ${ }^{14}$

\section{E. Faktor-Faktor yang Mempengaruhi Hasil belajar}

Hasil belajar terdiri dari dua kata yaitu hasil dan belajar. Hasil adalah perubahan yang terjadi melalui proses atau suatu kegiatan yang menunjang terajdinya perubahan. Belajar adalah suatu aktivitas atau suatu proses untuk memperoleh pengetahuan, meningkatkan keterampilan, memperbaiki perilaku, sikap, dan mengokohkan kepribadian. Dalam konteks menjadi tahu atau proses memperoleh hasil pengetahuan. ${ }^{15}$ Hasil belajar adalah perubahan terhadap diri seseorang baik dari aspek kognitf, psikomotorik, afektif melalui proses yang panjang dengan cara pengalaman belajar, latihan dan praktik pembelajaran disuatu lembaga pendidikan formal, informal dan nonformal.

Faktor-faktor yang mempengaruhi hasil belajar peserta didik dipengaruhi oleh faktor internal dan eksternal. Faktor internal terdiri dari faktor instrumental imput (penyesuaian kurikulum, kelengkapan sarana dan prasarana), faktor raw imput terdiri

\footnotetext{
${ }^{12}$ J.J Hasibuan dan Muljiono, Proses Belajar Mengajar (Bandung: PT. Rosdakarya, 1993), h. 31.

${ }^{13}$ Wina Sanjaya, Strategi Pembelajaran Beriorentasi Standar Proses Pendidikan (Jakarta: kencana Prenada Media Group, 2011), h. 152-153.

${ }^{14}$ Darwyn syah, Perencanaan Sistem Pengajaran Pendidikan Agama Islam (Cet. II; Jakarta: Gung Persada Press, 2007), h. 153.

${ }^{15}$ Suyono dan Hariyanto, Belajar dan Pembelajaran (Cet. IV; Bandung: PT. Remaja Rosdakarya, 2014), h. 9.
} 
dari kondisi fisiologis (sehatnya jasmani), kondisi psikologis (minat, kecerdasan, motif atau keinginan, motivasi atau semangat belajar, bakat dalam diri seseorang. Faktor eksternal terdiri dari lingkungan keluarga, lingkungan sekolah, lingkungan masyarakat. menurut peneliti ketiga dilingkungan pendidikan sangat berpengaruh dalam meningkatkan hasil belajar dan kepribadian peserta didik sehingga mendorong peserta didik lebih giat belajar.

\section{F. Penerapan Pembelajaran Inquiri Terhadap Hasil Belajar Pada Mata Pelajaran Fiqhi di Madrasah Aliyah Guppi Samata Kabupaten Gowa}

Penelitian ini adalah penelitian eksperimen semua atau quasi-eksperimental design. Bentuk desain eksperimen yang digunakan dalam penelitian ini adalah desain kelompok kontrol non-ekuvalen atau the nonequivalent control group design dengan desain ini, baik kelompok esperimen maupun kelompok kontrol dibandingkan, kelompok tersebut dipilih dan ditempatkan tampa melalui randomisasi. Subjek penelitian terdiri dari 40 peserta didik. 20 peserta didik dari siswa kelas $\mathrm{XI}_{\mathrm{A}}$ sebagai kelompok eksperimen dengan penerapan pembelajaran inquiri dan metode demonstrasi. 20 peserta didik dari kelas $\mathrm{XI}_{\mathrm{B}}$ dengan penerapan metode ceramah (uji pretest), metode diskusi (uji post-test) di Madrasah Aliyah Guppi Samata Kabupaten Gowa.

Metode yang digunakan pada uji pretest menggunakan metode ceramah, dan uji post-test menggunakan pembelajaran inquiri. Berdasarkan penelitian penerapan pembelajaran inquiri efektif digunakan untuk meningkatkan hasil belajar peserta didik pada mata pelajaran fiqhi di Madrasah Aliyah Guppi Samata Kabupaten Gowa. Penerapan pembelajaran inquiri termasuk suatu alternatif untuk mengembangkan ide-ide atau gagasan peserta didik, melatih menemukan jawaban dengan mandiri. Hasil penelitian menunjukkan penerapan pembelajaran inquiri layak untuk dikembangkan dan digunakan dalam proses belajar mengajar karena pembelajaran inquiri menunjukkan peningkatan yang lebih signifikan dibandingkan dengan metode ceramah. contoh peningakatan pada pembelajaran inquri kategori sangat baik diinterval 86-100, post-test I sebesar $20 \%$, Post-test II, III sebesar 35\%, post-test IV sebesar 50\%, sedangkan pada penerapan metode ceramah kategori sangat baik diinterval $73-87$, pretest I sebesar 40\%, pretest II, III sebesar $35 \%$, pretest IV sebesar $55 \%$. Hasil belajar mata pelajaran fiqhi antara kelas kontrol (metode ceramah, metode diskusi) dengan di kelas eksperimen (metode ceramah dan pembelajaran inquiri) pada variabel $\mathrm{X}_{1}$ di Madrasah Aliyah Guppi Samata Kabupaten Gowa menunjukkan penerapan pembelajaran inquri lebih unggul dibandingkan dengan metode ceramah dan diskusi. Penerapan pembelajaran inquiri di kelas eksperimen ditandai dengan semakin mengecilnya standar deviasinya, nilai rata-rata yang stabil dan, nilai maksimun dan minimun yang semakin meningkat. Presentase pengaruh penerapan pembelajaran inquiri sebesar $71,8 \%$ dan pengaruhnya bernilai positif dan meningkatakan kemampuan pemahaman peserta didik dalam mencapai hasil belajar yang maksimal, $28,2 \%$ dipengaruhi oleh faktor lain. 


\section{G. Penerapan Metode Demonstrasi Terhadap Hasil Belajar Pada Mata Pelajaran Fiqhi di Madrasah Aliyah Guppi Samata Kabupaten Gowa}

Berdasarkan penelitian penerapan penerapan metode demonstrasi efektif digunakan untuk meningkatkan hasil belajar peserta didik pada mata pelajaran fiqhi di Madrasah Aliyah Guppi Samata Kabupaten Gowa. mampu memfokuskan peserta didik di Madrasah Aliyah Guppi Samata kabupaten Gowa, sehingga perhatian peserta didik dan menimbulkan motivasi belajar, minat untuk belajar dan mengeluarkan ide-idenya setelah melaksanakan praktek secara langsung. Hasil penelitian menunjukkan penerapan metode demonstrasi layak untuk dikembangkan dan digunakan dalam proses belajar mengajar. Contoh peningakatan pada penerapan metode demonstrasi kategori sangat bagus diinterval 86-100, post-test I sebesar 20\%, Post-test II, III sebesar 30\%, post-test IV sebesar 40\%, sedangkan pada metode ceramah kategori sangat bagus diinterval 73-87, pretest I sebesar $30 \%$, pretest II,III sebesar $35 \%$, pretest IV sebesar $30 \%$. Hasil belajar mata pelajaran fiqhi antara kelas kontrol (metode ceramah, metode diskusi) dengan di kelas eksperimen (metode ceramah dan metode demonstrasi) pada variabel $\mathrm{X}_{2}$ di Madrasah Aliyah Guppi Samata Kabupaten Gowa menunjukkan penerapan metode demonstrasi lebih efektif dibandingkan dengan metode ceramah dan diskusi. Penerapan pembelajaran inquiri di kelas eksperimen ditandai dengan semakin mengecilnya standar deviasinya, nilai rata-rata yang stabil dan, nilai maksimun dan minimun yang semakin meningkat. Presentase pengaruh penerapan metode demonstrasi sebesar 78,1\% dan pengaruhnya bernilai positif dan meningkatakan kemampuan pemahaman peserta didik dalam mencapai hasil belajar yang maksimal.

\section{H. Pengaruh secara Simultan Penerapan Pembelajaran Inquiri dan Metode Demonstrasi Pada Mata Pelajaran Fiqhi di Madrasah Aliyah Guppi Samata Kabupaten Gowa.}

Nilai $R$ Square sebesar 0,778, hal itu menandakan hasil belajar mata pelajaran fiqhi dipengaruhi oleh penerapan pembelajaran inquiri dan metode demonstrasi sebesar $78,8 \%$.

\section{KESIMPULAN}

Dari pembahasan di atas, peneliti menyimpulkan sebagai berikut;

1. Terdapat peningkatan yang signifikan dan bernilai positif dari penerapan pembelajaran inquiri terhadap hasil belajar mata pelajaran fiqhi dan terdapat pengaruh penerapan pembelajaran inquiri terhadap hasil belajar pada mata pelajaran fiqhi di Madrasah Aliyah Guppi Samata Kabupaten Gowa.

2. Terdapat peningkatan yang signifikan dan bernilai positif dari penerapan metode demonstrasi terhadap hasil belajar mata pelajaran fiqhi dan terdapat pengaruh penerapan pembelajaran inquiri terhadap hasil belajar pada mata pelajaran fiqhi di Madrasah Aliyah Guppi Samata Kabupaten Gowa.

3. Hasil belajar pada mata pelajaran fiqhi menunjukkan penerapan pembelajaran inquiri lebih layak digunakan dan mengalami signifikansi dibandingkan dengan penerapan 
metode ceramah dan diskusi pada variabel $\mathrm{X}_{1}$. Hasil belajar pada mata pelajaran fiqhi menunjukkan penerapan metode demonstrasi lebih layak digunakan dan mengalami signifikansi dibandingkan dengan penerapan metode ceramah dan diskusi pada variabel $\mathrm{X}_{1}$ dan Terdapat pengaruh secara simultan penerapan pembelajaran inquiri terhadap hasil belajar mata pelajaran fiqhi di Madrasah Aliyah Guppi Samata Kabupaten Gowa.

\section{DAFTAR PUSTAKA}

A. Baki, H. Nasir. Metode pembelajaran Agama Islam. Cet. I; Yogyakarta: Eja Publisher, 2014.

Arifin, M. Ilmu Pendidikan Islam. Cet. II; Jakarta: PT. Bumi Aksara, 2006.

J.J Hasibuan dan Muljiono, Proses Belajar Mengajar, Bandung: PT. Rosdakarya, 1993.

Kartono, Kartini. Bimbingan dan Dasar-Dasar Pelaksanaan; Tekhnik Bimbingan Praktis. Cet. I; Jakarta: CV. Rajawali, 1985.

Krismanto, Beberapa Tekhnik, Model Dan Strategi dalam Pembelajaran Matematika, Yogyakarta: PPPG Matematika, 2003.

N.K, Roestiyah Strategi Belajar mengajar, Cet. V; Jakarta: Rineka Cipta, 1998.

Ramyulis, Metodologi Pendidikan Islam, Cet. VII; Jakarta: Radar Jaya Ofset, 2012.

Sagala, Syaiful. Konsep dan Makna Pembelajaran untuk Membantu Memecahkan Problematika Belajar dan Mengajar. Cet. VIII; Bandung: Alfabeta, 2010.

Sanjaya, Wina. Strategi Pembelajaran Beriorentasi Standar Proses Pendidikan. Jakarta: kencana Prenada Media Group, 2008.

Sanjaya,Wina. Strategi Pembelajaran Beriorentasi Standar Proses Pendidikan. Jakarta: kencana Prenada Media Group, 2011.

Suprihatiningrum, Jamil. Strategi Pembelajaran; Teori dan Aplikasi. Jogjakarta: Ar-Ruzz Media, 2013.

Suyono dan Hariyanto, Belajar dan Pembelajaran, Cet. IV; Bandung: PT. Remaja Rosdakarya, 2014.

syah, Darwyn. Perencanaan Sistem Pengajaran Pendidikan Agama Islam. Cet. II; Jakarta: Gung Persada Press, 2007.

Yaumi, Muhammad. Prinsip-Prinsip Desain Pembelajaran. Cet. IV; Jakarta: Kencana Prenada Media Group, 2016. 